\title{
Analysis of discrimination reversal in the rat
}

KHALIL A. KHAVARI, UNIVERSITY OF WISCONSIN, MILWAUKEE GEORGE A. HEISE, INDIANA UNIVERSITY

Rats learned a temporal discrimination reversals in a discrete trial operant conditioning situation. The rats responded with equally high probability to both $S^{+}$and $S^{-}$during the early parts of each session and subsequently reduced responding to $S^{-}$. When responding in $S^{-}$produced another $S^{-}$all rats significantly reduced responding in $S$.

Although a wealth of literature exists on the subject of discrimination reversals (Mackintosh, 1965), few attempts have been made to analyze systematically the development of the behavior. A notable exception is a comparative study by Gonzalez, Berger, \& Bitterman (1966) where an effort was made to analyze response components involved in the within-reversal performance of the Ss.

The purpose of the present study is to analyze the development of the discrimination reversal behavior and the pattern of responding employed by the rat. Method

The Ss were 15 naive, male albino rats of the Sprague-Dawley strain, between 90-120 days old at the beginning of the experiment. The apparatus consisted of two single-lever Skinner boxes with a light, a loudspeaker, and a liquid dispenser.

Twenty-hour water-deprived rats first learned to bar press for $9 \%$ sucrose solution and then were trained using a discrete trial procedure in which the trials were of 10 sec duration, spaced 10 sec apart. Any bar press during the intertrial interval postponed the onset of the next trial by $10 \mathrm{sec}$. The trial onset was indicated by the presentation of one of two complex stimuli: either a $1000 \mathrm{cps}$ tone at $85 \mathrm{~dB}$ and a continuous light, or a $1600 \mathrm{cps}$ tone at $85 \mathrm{~dB}$ and a 2/sec flashing light. Both stimuli were programmed to occur equally often in a random sequence.

In the preliminary phase of discrete-trial training, a single bar press in the presence of either stimuli produced a drop of sugar water and terminated the trial. During the subsequent discrimination phase, responses in the presence of only one of the two stimuli produced the reinforcement. In the first discrimination session the reinforced stimulus $\left(S^{+}\right)$and the nonreinforced stimulus $\left(\mathrm{S}^{-}\right)$were randomly determined for each rat. Each rat was given a maximum of 480 trials per daily session and was maintained on a given $S^{+-} S^{-}$ discrimination for as many session as was required to attain the discrimination criterion. Once the criterion was reached, the session was terminated and in the next session the $\mathrm{S}^{+}-\mathrm{S}^{-}$were reversed. The criterion for the acquisition of the discrimination was a response to 10 reinforced trials without any response to the intervening nonreinforced trials.
A response during $\mathrm{S}^{+}$always resulted in trial termination and the delivery of a drop of sugar water. Through Reversal 3, responses made during $S^{-}$had no consequences. Regardless of responses, the $S^{-}$trial always remained on for the full $10 \mathrm{sec}$. The probabiliy of either an $S^{-}$or $S^{+}$trial following an $S^{-}$trial was always 0.5 .

Beginning with Reversal 4 the Ss were assigned randomly into two groups of seven (Group A) and eight (Group B). For the rats in Group $A$ a new contingency was introduced. Whenever a rat responded to an $\mathrm{S}^{-}$, the following trial was also an $\mathrm{S}^{-}, 1 . e .$, every time the rat responded in $\mathrm{S}^{-}$, it changed the probabilities associated with the next trial from $P\left(S^{+}\right)=$ $P\left(S^{-}\right)=0.5$ to $P\left(S^{-}\right)=1.0$ and $P\left(S^{+}\right)=0$. This procedure is called the $S^{-}$repeat procedure ( $S_{R E P}^{-}$). One nonresponse in $\mathrm{S}^{-}$was required to return the trial presentations to the regular schedule where $P\left(S^{+}\right)=P\left(S^{-}\right)=$ 0.5 . Group $B$ continued on the regular schedule, through Reversal 8, without being subjected to the $\mathrm{S}^{-}$repeat procedure (No $S^{-}$REP). Beginning with Reversal 9 Group $B$ was also placed in the $\mathrm{S}^{-} \mathbf{R E P}$.

The Mann-Whitney U-test was employed in all tests of significance reported below, unless specified otherwise.

\section{Results and Discussion}

Mastery of the first discrimination, Reversal 0 , required 590 trials on the average while Reversal 1 was most difficult with mean trials to criterion of 1179 (Fig. 1). This difference of performance on the two sessions was significant as determined by the correlated $t$ test $(t=5.12$, $d f=14, p<.001)$. A gimilar decrement following the first reversal has been reported by many other investigators (e.g., Gonzalez et al, 1966). In Reversal 4 where $\mathrm{S}^{-} \mathrm{REP}$ was introduced for Group A while Group B continued under No $\mathrm{S}^{-} \mathrm{REP}$, the former group required significantly fewer trials to criterion $(U=1, p<.001)$. The performance of Group A remained superior through Reversal 8. In Reversal 9, when Group B was also placed under $\mathrm{S}^{-} \mathrm{REP}$, the performance of the two groups did not differ significantly $(U=15, p>.076)$.

Two factors presumably account for the superior reversal performance obtained in the S-REP condition. (1) The greater proportion of $\mathrm{S}^{-}$trials presented under the $S^{-}$REP than under the No $S_{\text {REP }}$ condition would be expected to lead to earlier extinction of responding to $\mathrm{S}^{-}$in $\mathrm{S}^{-}$REP. (2) Whereas in the NoS ${ }^{-}$REP condition responses to $S$ were merely extinguished, response to $S^{-}$in the $S^{-}$REP condition were also punished, by presentation of $\mathrm{S}^{-}$on the next trial. Studies demonstrating that a period associated with extinction (a 


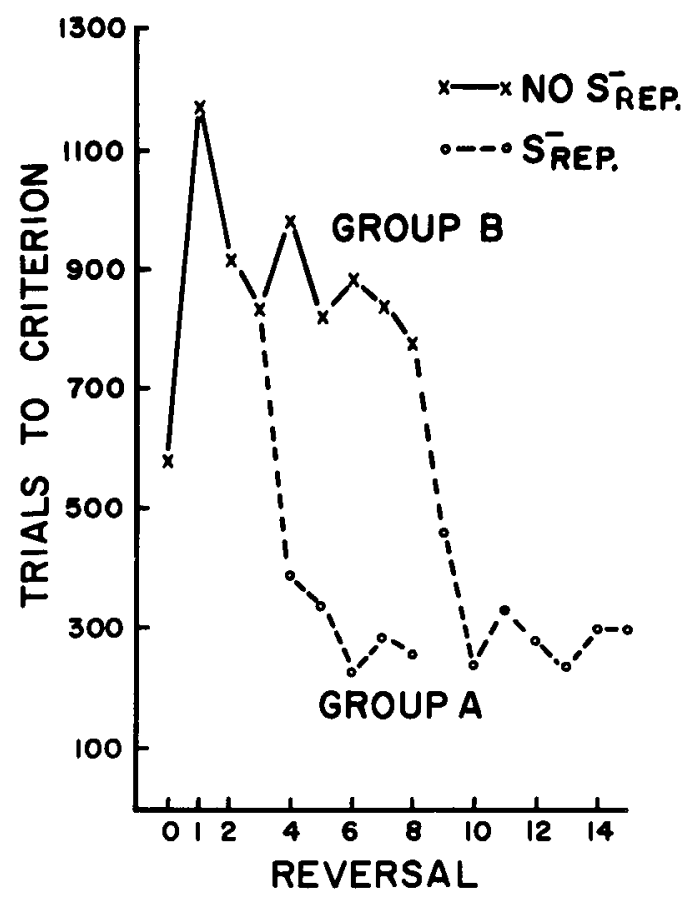

Fig. 1. Effects of $S^{-}$REP versus NO $S^{-}$REP procedures on mean number of trials to criterion of successive reversals for the two groups of rats.

"time out," or $\mathrm{S}^{-}$) can serve as a punishing stimulus have been summarized by Azrin \& Holz (1966).

Analysis of within-reversal learning of the rats showed that at the beginning of each session the rats responded to both $\mathrm{S}^{+}$and $\mathrm{S}^{-}$with equally high probability. Average value of response probability to the first 10 trials was near 1.0 for all rats in all sessions with no difference between responses to $\mathrm{S}^{+}$versus responses to $\mathrm{S}^{-}$. During the session, responses to $\mathrm{S}^{-}$ gradually decreased while responses to $\mathrm{S}^{+}$remained at full strength. This response pattern was always present at the beginning of each new reversal, and also when the rat failed to reach the discrimination criterion in one session and therefore received the same discrimination $24 \mathrm{~h}$ later. This same response pattern was also observed when, having reached the criterion, the rat was taken out of the box for approximately $3 \mathrm{~min}$, and then returned to the box and given the same discrimination problem. Although in this latter case the rat behaved as if a new discrimination had been introduced by responding initially to both $\mathrm{S}^{+}$and $\mathrm{S}^{-}$, it required far fewer trials to attain criterion than on its preceding run on the same discrimination.

The response pattern just described is clearly incompatible with a conception of reversal learning in which the tendency to respond during $\mathrm{S}^{+}$increases incrementally with each reinforced response, while the tendency to respond to $\mathrm{S}^{-}$concurrently decreases with each nonreinforced response. Nor does the relative tendency to respond to the two stimuli achieved at the end of the session or atcriterion remain "fixed" between sessions. Rather, the rat begins each new session with an approximately equal tendency to respond to the two stimuli. The tendency to respond to $\mathrm{S}^{-}$ then gradually weakens due to nonreinforcement, followed between sessions by a surprisingly rapid "spontaneous recovery" of the response to the previously extinguished stimulus.

\section{References}

AZRIN, N. H., \& HOLZ, W. C. Punishment. W. K. Honig (Ed.), Operant behavior: areas of research and application. New York: AppletonCentury-Crofts, 1966. Pp. 380-447.

GONZALES, R. C., BFRGER, B. D., \& BITTERMAN, M. E. Improvement in habit-reversal as a function of amount of training per reversal and other variables. Amer. J. Psychol, 1966, 79, 517-530.

MACKINTOSH, N. J. Selective attention in animal discrimination learning. Psychol. Bull., 1965, 64, 124-150.

Note

1. This research was supported by NIH research grant MH-06997 and the Graduate School of the University of Wisconsin-Milwaukee. 